\title{
An experimental study on hydrothermal degradation of cubic-containing translucent zirconia
}

\author{
Santiphab Kengtanyakich, Chaimongkon Peampring* \\ Department of Prosthetic Dentistry, Faculty of Dentistry, Prince of Songkla University, Hadyai, Songkhla, Thailand
}

\begin{abstract}
PURPOSE. The aims of this study were to investigate mechanical properties and hydrothermal degradation behaviour of the cubic-containing translucent yttrium oxide stabilized tetragonal zirconia polycrystal (Y-TZP). MATERIALS AND METHODS. Four groups of Y-TZP (T, ST, XT, and P), containing different amount of cubic crystal, were examined. Specimens were aged by autoclaving at $122^{\circ} \mathrm{C}$ under 2 bar pressure for $8 \mathrm{~h}$. Phase transformation was analyzed using X-ray diffraction (XRD) to measure phase transformation $(\mathrm{t} \rightarrow \mathrm{m})$. KruskalWallis test was used to determine the difference. Surface hardness, biaxial flexural strength, and fracture toughness in values among the experimental groups and verified with Wilcoxon matched pairs test for hardness values and Mann Whitney $U$ for flexural strength and fracture toughness. RESULTS. XRD analysis showed no monoclinic phase in XT and P after aging. Only Group T showed statistically significant decreases in hardness after aging. Hydrothermal aging showed a significant decrease in flexural strength and fracture toughness in group $\mathrm{T}$ and $\mathrm{ST}$, while group XT and $\mathrm{P}$ showed no effect of aging on fractural strength and fracture toughness with $P<$.05. CONCLUSION. Hydrothermal aging caused reduction in mechanical properties such as surface hardness, biaxial flexural strength, and fracture toughness of Y-TZP zirconia. However, cubic-containing zirconia (more than $30 \%$ by volume of cubic crystal) was assumed to have high resistance to hydrothermal degradation. Clinical significance: Cubic-containing zirconia could withstand the intraoral aging condition. It could be suggested to use as a material for fabrication of esthetic dental restoration. [J Adv Prosthodont 2020;12:265-72]
\end{abstract}

KEYWORDS: Zirconia ceramic; Mechanical properties; Hydrothermal degradation; Cubic phase; Fracture toughness

\section{INTRODUCTION}

Yttrium-stabilized tetragonal zirconia polycrystal (Y-TZP) has excellent strength and fracture toughness after machining and sintering, which are higher than those of other den-

Corresponding author:

Chaimongkon Peampring

Department of Prosthetic Dentistry, Faculty of Dentistry, Prince of Songkla

University, Hadyai, Songkla, 90112, Thailand

Tel.+6681-6912241: e-mail, mongkon.5c@gmail.com

Received January 22, 2020 / Last Revision April 9, 2020 / Accepted

August 21, 2020

(C) 2020 The Korean Academy of Prosthodontics

This is an Open Access article distributed under the terms of the Creative Commons Attribution Non-Commercial License (http://creativecommons. org/licenses/by-nc/4.0) which permits unrestricted non-commercial use, distribution, and reproduction in any medium, provided the original work is properly cited.

The study was provided by the Technologies and Materials in Digital Dentistry Research Unit, Faculty of Dentistry, Prince of Songkla University, Songkhla Province, Thailand. tal ceramics. ${ }^{1,2}$ Tetragonal zirconia structure has been retained at room temperature by application of a stabilizer, yttrium oxide $\left(\mathrm{Y}_{2} \mathrm{O}_{3}\right)$. However, the metastable tetragonal phase can return to a stable monoclinic phase due to the occurrence of local stress and/or humid environments. ${ }^{3}$ The volume expansion associated with the tetragonal to monoclinic transformation $(\mathrm{t} \rightarrow \mathrm{m})$ results in compressive stress inside the transformed region, and consequently the crack propagation in the ceramic terminates. ${ }^{1}$

The $\mathrm{t} \rightarrow \mathrm{m}$ transformation can spontaneously occur at low temperature especially in the presence of water, known as aging, hydrothermal degradation or low-temperature degradation (LTD). ${ }^{4}$ Many studies indicated that the adverse effect of the LTD was the deleterious effect on mechanical and physical properties such as flexural strength, surface roughness and hardness. ${ }^{5-10}$ Increasing amount of $\mathrm{Y}_{2} \mathrm{O}_{3}$ stabilizer tends to alter the phase structure from tetragonal to cubic phase resulting in increased translucency and improved hydrothermal aging resistance. ${ }^{11-14}$ The amount of 
cubic crystal structures seems to have an effect on the microstructure of zirconia materials, ${ }^{15}$ particularly mechanical properties. ${ }^{14}$ Nowadays, the studies have reported that increasing amount of cubic phase in zirconia can improve translucency of cubic-containing zirconia compared to conventional zirconia. ${ }^{12,14,16}$ However, limited numbers of studies are available regarding the mechanical properties and degradation behavior of cubic zirconia for monolithic restorations.

The aims of this study were to investigate the mechanical properties and hydrothermal degradation behaviour among commercial translucent zirconia products containing different amount of cubic crystal $(<30 \%, 30-50 \%$, and $>50 \%$ cubic phase) and compare them with conventional zirconia $(0 \%$ cubic phase).

\section{MATERIALS AND METHODS}

Four different commercially available zirconia materials were tested in this study (Table 1). A water-cooled precision saw (Buehler, ISOMET 4000, Buehler Ltd., Lake Bluff, IL, USA) was used to section cylindrical zirconia blocks into disk-shaped ( $\mathrm{n}=22$ / each group) and rectangular-shaped specimens ( $\mathrm{n}=10 /$ each group). All zirconia specimens were fully crystallized using high temperature furnace (VITA Zyrcomat ${ }^{\circledR} 6000$ MS, Vita Zahnfabrik H. Rauter GmbH \& Co. KG, Bad Säckingen, Germany) according to respective manufacturer's recommendations (Table 2). The final dimensions for each test specimen were confirmed with a digital caliper (Mitutoyo, Mitutoyo Manufacturing Company Ltd., Kawasaki, Japan); $15 \mathrm{~mm}$ diameter, $1 \mathrm{~mm}$ thickness for disk-shaped specimens, and $24 \times 6 \times 3 \mathrm{~mm}^{3}$ for rectangular-shaped specimens. Afterwards, all specimens were ultrasonicated (Model: 460/M, Elma Schmidbauer $\mathrm{GmbH}$, Singen, Germany) in distilled water for $10 \mathrm{~min}$ before testing.

Scanning electron microscopy (SEM, FEI Quanta 400) was used to characterize the microstructure of four as sintered groups. The result of grain size in each group was reported in average grain size $(\mu \mathrm{m})$. Hydrothermal aging simulation were set up using an autoclave (TOMY ES 215/ ES-315, Tomy Kogyo Co., Ltd., Nerima, Japan) at $122^{\circ} \mathrm{C}$ under 2 bar pressure over a period of $8 \mathrm{~h}$. Crystal structure identification of experimented zirconia was done by X-ray diffraction analysis (XRD, Philips X'Pert MPD, Philips, Eindhoven, Netherlands) using $\mathrm{Cu}-\mathrm{K} \alpha$ radiation from 5 $90^{\circ}(2 \theta)$. To measure phase structure before and after aging, specimens were subject to XRD to determine the peak position and composition. Peaks from the XRD output were compared to XRD library data to identify the occurrence phase structure. As a result, the tetragonal to monoclinic phase transformation was detected at the surface of the specimens. The volume fractions of transformed monoclinic zirconia $\left(\mathrm{V}_{\mathrm{m}}\right)$ were calculated from the integral intensities of the monoclinic and tetragonal peaks $\left(\mathrm{X}_{\mathrm{m}}\right)$. This characterization was based on the following equations proposed by Garvie and Nicholson ${ }^{17}$ and Toraya et al $^{18}$

$$
\mathrm{X}_{\mathrm{m}}=\left[\operatorname{Im}(111)+\operatorname{Im}\left(111^{-}\right)\right] /\left[\operatorname{Im}(111)+\operatorname{Im}\left(111^{-}\right)+\operatorname{It}(101)\right]
$$

Table 1. Study materials

\begin{tabular}{|c|c|c|c|c|c|c|}
\hline Material & Type & Code & Components (wt\%) & $\begin{array}{l}\text { Amount of cubic } \\
\text { structure (\%) }\end{array}$ & Lot number & Manufacturer \\
\hline Vita YZ T & 3Y-TZP & $\mathrm{T}$ & $\begin{array}{l}\mathrm{ZrO}_{2}(90-95), \mathrm{Y}_{2} \mathrm{O}_{3}(4-6), \mathrm{HfO}_{2}(1-3) \\
\mathrm{Al}_{2} \mathrm{O}_{3}(0-1), \text { Pigments }(0-1)\end{array}$ & 0 & 73830 & $\begin{array}{l}\text { VITA Zahnfabrik, } \\
\text { Bad Säckingen, } \\
\text { Germany }\end{array}$ \\
\hline Vita YZ ST & 4Y-TZP & ST & $\begin{array}{l}\mathrm{ZrO}_{2}(88-93), \mathrm{Y}_{2} \mathrm{O}_{3}(6-8), \mathrm{HfO}_{2}(1-3), \\
\mathrm{Al}_{2} \mathrm{O}_{3}(0-1), \text { Pigments }(0-1)\end{array}$ & $<30$ & 65890 & $\begin{array}{l}\text { VITA Zahnfabrik, } \\
\text { Bad Säckingen, } \\
\text { Germany }\end{array}$ \\
\hline Vita YZ XT & $5 Y-T Z P$ & XT & $\begin{array}{l}\mathrm{ZrO}_{2}(86-91), \mathrm{Y}_{2} \mathrm{O}_{3}(8-10), \mathrm{HfO}_{2}(1-3) \\
\mathrm{Al}_{2} \mathrm{O}_{3}(0-1), \text { Pigments }(0-1)\end{array}$ & $30-50$ & 61960 & $\begin{array}{l}\text { VITA Zahnfabrik, } \\
\text { Bad Säckingen, } \\
\text { Germany }\end{array}$ \\
\hline Prettau Anterior & 6Y-TZP & $P$ & $\begin{array}{l}\mathrm{ZrO}_{2} \text { (Main component), } \mathrm{Y}_{2} \mathrm{O}_{3}(<12) \\
\mathrm{Al}_{2} \mathrm{O}_{3}(<1), \mathrm{SiO}_{2}(<0.02), \mathrm{Fe}_{2} \mathrm{O}_{3}(<0.02)\end{array}$ & $>50$ & ZB6124B & $\begin{array}{l}\text { Zirkonzahn } \mathrm{GmbH} \text {, } \\
\text { Bruneck, Italy }\end{array}$ \\
\hline
\end{tabular}

Table 2. Sintering protocol of each group

\begin{tabular}{ccccc}
\hline Group & Heating rate $\left({ }^{\circ} \mathrm{C} / \mathrm{min}\right)$ & Final temperature $\left({ }^{\circ} \mathrm{C}\right)$ & Holding time $(\mathrm{min})$ & Cooling protocol \\
\hline $\mathrm{T}$ & 17 & 1530 & 120 & Cooling off at $100 \%$ to $200^{\circ} \mathrm{C}$ \\
$\mathrm{ST}$ & 8 & 1530 & 120 & Cooling off at $100 \%$ to $200^{\circ} \mathrm{C}$ \\
$\mathrm{XT}$ & 4 & 1450 & 120 & $\mathrm{Cooling} \mathrm{off} \mathrm{at} 100 \%$ to $200^{\circ} \mathrm{C}$ \\
$\mathrm{P}$ & 8 & 1500 & 120 & Cooling rate $8^{\circ} \mathrm{C} / \mathrm{min}$ to $50^{\circ} \mathrm{C}$ \\
\hline
\end{tabular}




$$
\mathrm{V}_{\mathrm{m}}=1.311 \mathrm{Xm} /[1+0.311 \mathrm{Xm}]
$$

where $\operatorname{Im}(111)$ and $\operatorname{Im}\left(111^{-}\right)$represent the intensity of monoclinic phase peaks $\left(2 \theta=28^{\circ}\right.$ and $2 \theta=31.2^{\circ}$, respectively) and $\mathrm{I}_{\mathrm{t}(101)}$ represent the intensity of tetragonal phase peak $\left(2 \theta=30^{\circ}\right)$. All data of control groups (no aging) and aging groups were compared.

The surface hardness was measured on disk-shaped specimens $(n=5)$ by the indentation method using Vickers microhardness test (Mitutoyo, Model: HM-211, Mitutoyo Corporation, Kawasaki, Japan) with load $1 \mathrm{~kg}$ for $10 \mathrm{~s}$. Five indents were placed in each specimen, and the Vickers hardness was calculated using the following equation: ${ }^{19}$

$\mathrm{Hv}=(1.8544 \mathrm{P}) d^{2}$

where $\mathrm{Hv}$ is the Vickers hardness, P is the applied load (kg), and $d$ is the mean indentation diagonal length ( $\mathrm{mm}$ ).

Afterwards, the same specimen was hydrothermal aged and microhardness test was repeatedly evaluated to compare with results of the specimen before aging.

The biaxial flexural strength testing was performed according to ISO standard number $6872 .{ }^{20}$ Disk-shaped specimens $(n=5)$ were positioned with the hydrothermallyaged surface facing down on three support balls $(\varnothing=2.5$ $\mathrm{mm})$, which were placed $10 \mathrm{~mm}$ apart from each other in a triangular position. A flat circular tungsten piston $(\varnothing=1.6$ $\mathrm{mm})$ was used to apply an increasing load $(0.5 \mathrm{~mm} / \mathrm{min})$ until catastrophic failure occurs using a universal testing machine (Lloyd instruments, Model LRX-Plus, AMETEK Lloyd Instrument Ltd., Hamphshire, UK). Biaxial flexural strength was calculated according to this following equation:

$$
\sigma=[-0.2387 \mathrm{P}(\mathrm{X}-\mathrm{Y})] / \mathrm{b}^{2}
$$

where $\sigma$ is the maximum tensile stress $(\mathrm{MPa}), \mathrm{P}$ is the total load to fracture $(\mathrm{N}), \mathrm{b}$ is the thickness at fracture origin $(\mathrm{mm})$, and $\mathrm{X}$ and $\mathrm{Y}$ are calculated according to:

$$
\begin{aligned}
& \left.\mathrm{X}=(1+\nu) \ln \left(\mathrm{r}_{2} / \mathrm{r}_{3}\right)^{2}+[(1-\nu) / 2)\right]\left(\mathrm{r}_{2} / \mathrm{r}_{3}\right)^{2} \\
& \mathrm{Y}=(1+\nu)\left[1+\ln \left(\mathrm{r}_{1} / \mathrm{r}_{3}\right)^{2}\right]+(1-\nu)\left(\mathrm{r}_{1} / \mathrm{r}_{3}\right)^{2}
\end{aligned}
$$

where $\nu$ is Poisson's ratio $(\nu=0.30),{ }^{21} \mathrm{r} 1$ is the radius of the support circle $(6.05 \mathrm{~mm}), \mathrm{r}_{2}$ is the radius of the loaded area $(0.8 \mathrm{~mm})$, and $\mathrm{r} 3$ is the radius of the specimen.

The biaxial flexural strength testing was performed on both specimens with and without hydrothermal aging and compared statistically.

The fracture toughness evaluation was performed on both specimens with and without hydrothermal aging. The test was set by using the single-edged-notched-beam (SENB) method. Rectangular-shaped specimens $(\mathrm{n}=10)$ were prepared according to the previous study. ${ }^{22}$ For the SENB test set-up (Fig. 1), a notch was created on a specimen using a 0.12 -mm-thick diamond disk equipped on a vertical milling machine (Mini vertical milling machine, Model CH-10M, Chung Hsiwh Industrial Co., Ltd., Ningbo, China). The specimens were cleaned ultrasonically in distilled water for $10 \mathrm{~min}$ and air dry for $20 \mathrm{~s}$ before testing.

All test specimens were subjected to a three-point bending fixture equipped in a universal testing machine and loaded until fracture with a crosshead speed of $0.5 \mathrm{~mm} / \mathrm{min}$. Two halves of the broken specimens were evaluated to measure the notch depth under a stereoscopic microscope

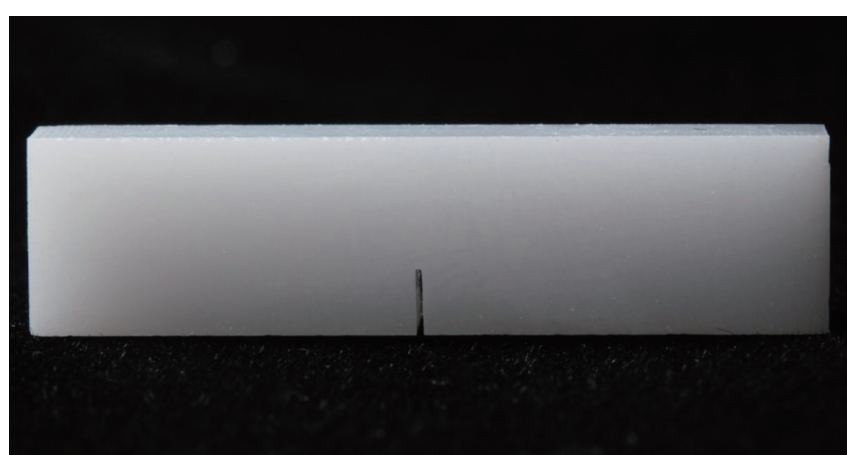

Fig. 1. Geometry of single-edged-notched-beam (SENB) test specimen.

(Nikon, smz1500, Nikon Instech Co., Ltd., Tokyo, Japan) . The depth, a, was the average of six values at three locations of the notch, middle point, and two sides of each section. The fracture toughness value $\left(\mathrm{K}_{\mathrm{IC}}\right)$ was calculated according to the following equations: $:^{22}$

$$
\begin{aligned}
\mathrm{K}_{\mathrm{IC}}= & {\left[\mathrm{F}_{\mathrm{c}} L((a / d))\right] / b d^{3 / 2} } \\
(a / d)= & 2.9(a / d)^{1 / 2}-4.6(a / d)^{3 / 2}+21.8(a / d)^{5 / 2} \\
& -37.6(a / d)^{7 / 2}+38.7(a / d)^{9 / 2}
\end{aligned}
$$

where $F_{c}$ is the critical load or the maximum load $(M N)$, $d$ is the specimen thickness (m), $b$ is the specimen width (m), $L$ is the span length between supports $(0.016 \mathrm{~m}), a$ is the notch depth $(\mathrm{m})$ and $(a / b)$ is the stress intensity shape factor. The actual values of $a$ and $d$ of each specimen were used.

Descriptive statistics were conducted for phase characterization. Mean and standard deviations of all data for each experiment were calculated. Assessment of normality distribution and homogeneity of variance were carried out using the Shapiro-Wilk test and Levene's test, respectively. Because the data was not normally distributed and homogeneity of variance was not equal in each group, so the parametric test cannot be used in this study. The Kruskal-Wallis test was used to determine the significant difference in hardness, flexural strength, and fracture toughness values between various types of zirconia in relation to aging condition. When a significant difference was detected, it was then verified with Wilcoxon matched pairs test for hardness values and Mann Whitney $U$ test for flexural strength and fracture toughness values. The statistical analysis was done using SPSS software, version 24.0 (IBM Corporation, Armonk, NY, USA) to detect statistically significant differences $(\alpha=.05)$.

\section{RESULTS}

SEM images of the as-sintered specimens were shown in Fig. 2. The average grain size for group T, ST, and XT were $1.42,1.35$, and $1.57 \mu \mathrm{m}$, respectively. Group P had the largest average grain sizes of $2.28 \mu \mathrm{m}$. 



Fig. 2. Scanning electron microscope images of four groups after sintering. (A) Group T, (B) Group ST, (C) Group XT, (D) Group P (magnification $\times 20000)$.
No monoclinic phase was detected in all material groups before aging. The amount of tetragonal to monoclinic phase transformation increased after aging in $\mathrm{T}$ and $\mathrm{ST}$ groups, up to $16.45 \%$ and $5.06 \%$ respectively, as opposed to undetectable amount of monoclinic phase after aging in XT and P groups (Fig. 3, Fig. 4). The hardness value for the each group at before and after aging was showed in Table 3. Before aging, the mean hardness values showed no significant differences among the material groups. Group T showed statistically significant decrease in hardness after aging $(P<.05)$ The mean flexural strengths in group $\mathrm{T}$ and ST were significantly higher than those in group XT and P in specimens without aging. Groups T and ST were significant lower in flexural strength in hydrothermally-aged specimens compared to specimens without aging. However, group XT and P showed no significant difference in flexural strength between with and without aging (Table 4). Fracture toughness values showed statistical differences amongst the material groups and aging conditions $(P<.05)$. Mann Whitney $U$ test analysis showed fracture toughness in no aging specimens in group in the following order: T $>$ ST $>$ XT, P. With aging, the fracture toughness of the group XT and $\mathrm{P}$ were statistically the same, whereas the fracture toughness showed statistically significant decreases for group T and ST $(P<.05)$ (Table 5).
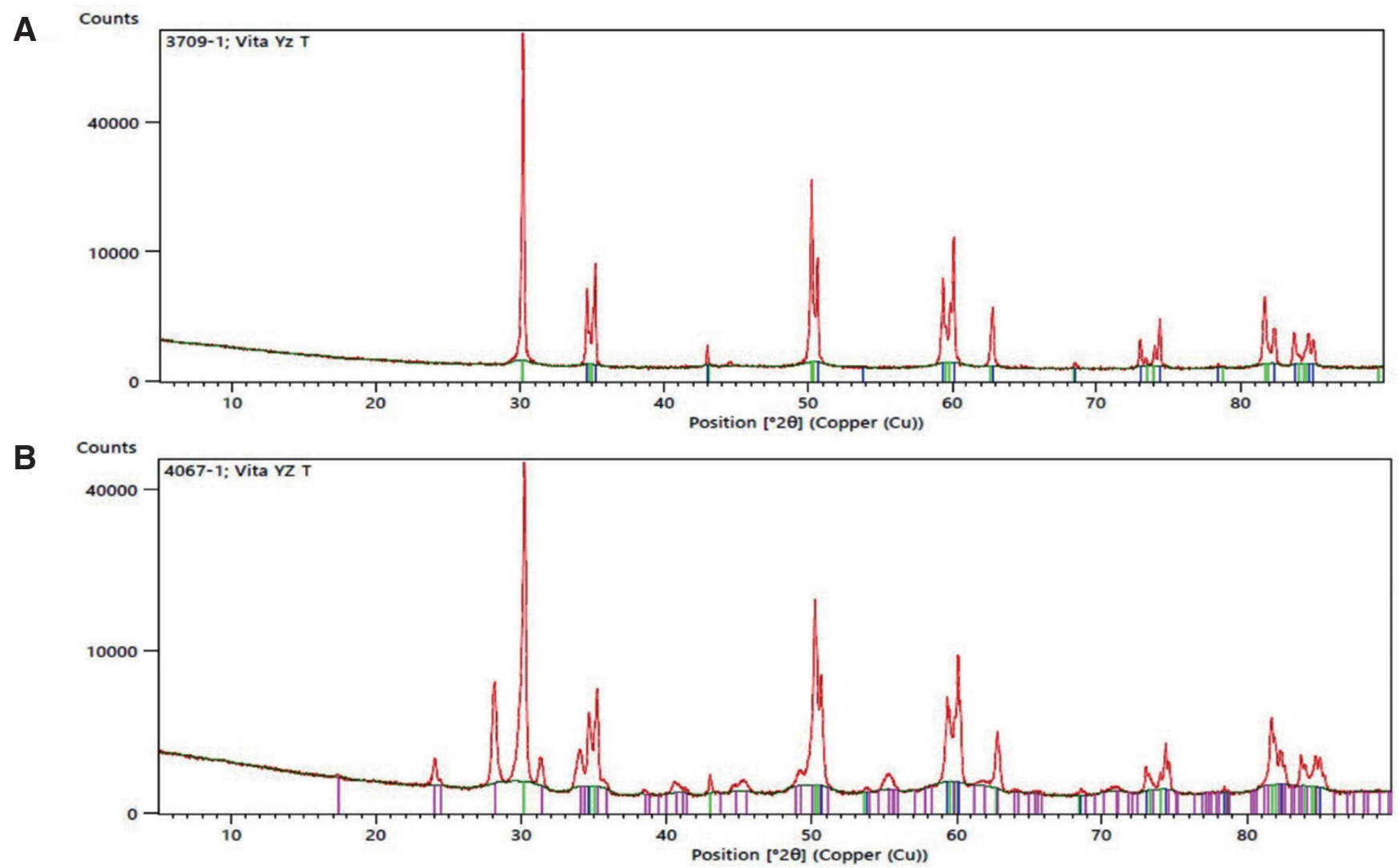

Fig. 3. X-ray diffraction analysis of group $\mathrm{T}(\mathrm{A})$ before and (B) after hydrothermal aging. 
A

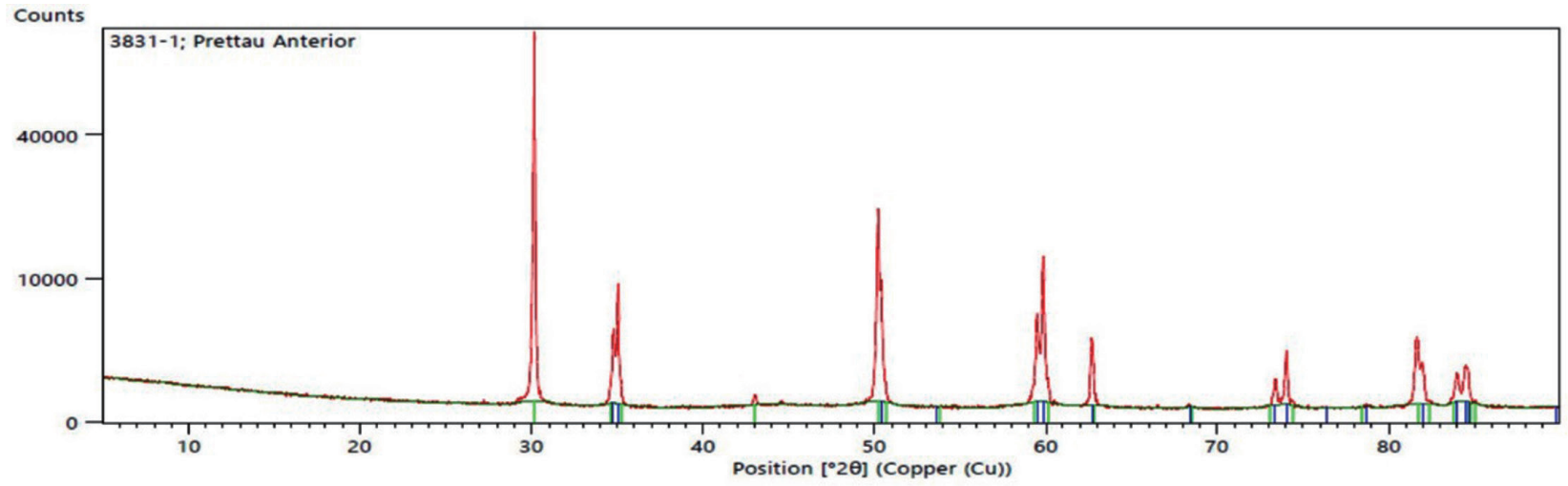

B counts

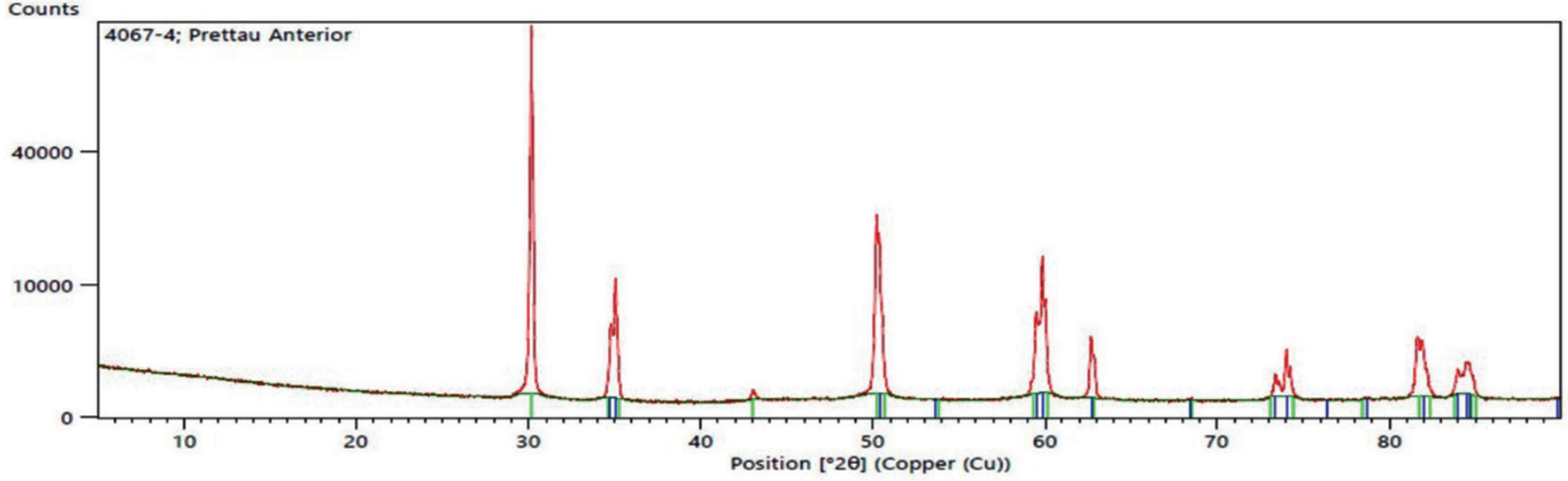

Fig. 4. X-ray diffraction analysis of group $\mathrm{P}(\mathrm{A})$ before and (B) after hydrothermal aging.

Table 3. Mean \pm SD and medians of hardness (GPa)

\begin{tabular}{ccccc}
\hline \multirow{2}{*}{ Group } & \multicolumn{2}{c}{ Before aging } & \multicolumn{2}{c}{ After aging } \\
& Mean $(\mathrm{SD})$ & Median & Mean (SD) & Median \\
\hline $\mathrm{T}$ & $13.65 \pm 0.21^{\mathrm{Aa}}$ & 13.65 & $12.58 \pm 0.15^{\mathrm{Bb}}$ & 12.61 \\
$\mathrm{ST}$ & $13.96 \pm 0.22^{\mathrm{Aa}}$ & 13.94 & $13.60 \pm 0.22^{\mathrm{Aa}}$ & 13.66 \\
$\mathrm{XT}$ & $13.62 \pm 0.22^{\mathrm{Aa}}$ & 13.70 & $13.62 \pm 0.27^{\mathrm{Aa}}$ & 13.70 \\
$\mathrm{P}$ & $13.72 \pm 0.18^{\mathrm{Aa}}$ & 13.74 & $13.57 \pm 0.16^{\mathrm{Aa}}$ & 13.64 \\
\hline
\end{tabular}

$\star_{A}, \mathrm{~B}$ Different letters present significant differences between materials $(P<.05)$.

a, b Different letters present significant differences between aging conditions $(P$ $<.05)$.
Table 5. Mean $\pm \mathrm{SD}$ and medians of fracture toughness $\left(\mathrm{MPa} \mathrm{m}^{1 / 2}\right)$

\begin{tabular}{crrrr}
\hline \multirow{2}{*}{ Group } & \multicolumn{2}{c}{ Without aging } & \multicolumn{2}{c}{ With aging } \\
& Mean $(\mathrm{SD})$ & Median & Mean (SD) & Median \\
\hline $\mathrm{T}$ & $15.49 \pm 1.08^{\mathrm{Aa}}$ & 15.91 & $11.56 \pm 0.45^{\mathrm{Ab}}$ & 11.60 \\
ST & $10.01 \pm 0.58^{\mathrm{Ba}}$ & 9.88 & $7.45 \pm 1.16^{\mathrm{Bb}}$ & 6.99 \\
XT & $3.30 \pm 0.40^{\mathrm{Ca}}$ & 3.16 & $3.19 \pm 0.22^{\mathrm{Ca}}$ & 3.22 \\
$\mathrm{P}$ & $3.48 \pm 0.36^{\mathrm{Ca}}$ & 3.41 & $3.46 \pm 0.36^{\mathrm{Ca}}$ & 3.38 \\
\hline
\end{tabular}

* A, B, C Different letters present significant differences between materials $(P<.05)$

${ }^{a, b}$ Different letters present significant differences between aging conditions $(P$ $<.05)$

Table 4. Mean $\pm \mathrm{SD}$ and medians of flexural strength (MPa)

\begin{tabular}{ccccc}
\hline \multirow{2}{*}{ Group } & \multicolumn{2}{c}{ Without aging } & \multicolumn{2}{c}{ With aging } \\
& Mean (SD) & Median & Mean (SD) & Median \\
\hline$T$ & $872.73 \pm 124.16^{\mathrm{Aa}}$ & 821.82 & $705.75 \pm 55.54^{\mathrm{Ab}}$ & 728.20 \\
ST & $779.92 \pm 32.77^{\mathrm{Aa}}$ & 780.91 & $641.19 \pm 64.60^{\mathrm{Ab}}$ & 674.67 \\
XT & $463.37 \pm 39.10^{\mathrm{Ba}}$ & 477.48 & $473.67 \pm 74.89^{\mathrm{Ba}}$ & 467.55 \\
$P$ & $450.60 \pm 77.34^{\mathrm{Ba}}$ & 494.20 & $483.23 \pm 33.64^{\mathrm{Ba}}$ & 485.14 \\
\hline
\end{tabular}

*A, B Different letters present significant differences between materials $(P<.05)$.

a, b Different letters present significant differences between aging conditions $(P<.05)$. 


\section{DISCUSSION}

The increased demands of patients for esthetic restorations have been driving the development of dental restorative materials from conventional zirconia to highly translucent monolithic zirconia ceramic materials. Fabrication of translucent zirconia can be performed in many ways: changing the composition and grain size, and altering the sintering conditions and material thickness. ${ }^{23-27}$ Recently, many companies have been improving zirconia translucency by trying to retain more cubic structure at room temperature. This recent study used various commercial products, which could be classified based upon the amount of cubic structure as low $(<30 \%)$, moderate $(30-50 \%)$, and high cubic-containing zirconia $(>50 \%)$.

This study investigated the mechanical properties and accelerated aging characteristics of 3 categories of commercial translucent zirconia as mentioned previously $(<30 \%$, $30-50 \%$, and $>50 \%$ cubic-containing) under extreme in vitro conditions. From the result of this study, the null hypothesis that the mechanical properties of the cubic zirconia material would not be influenced by hydrothermal aging was rejected. The strategy of increasing the amount of cubic crystals to improve translucency of monolithic zirconia resulted in reduction of mechanical properties such as flexural strength and fracture toughness. ${ }^{28}$ Fracture toughness is a mechanical property that describes the resistance of brittle materials to catastrophic propagation of flaws under applied stress. ${ }^{21}$ This in vitro study evaluated the fracture toughness by using SENB method because it is considered to be a reliable method. ${ }^{22}$ Also, specimen preparation, especially notch creation, was not technique sensitive.

The transformation toughening is a process in which the stresses induce transformation of tetragonal crystal to monoclinic crystal in stabilized zirconia. This process is associated with a large volume expansion (3-5\%) resulting in occurrence of compressive stresses opposing crack opening and acts to increase resistance to crack propagation. ${ }^{29}$ Zirconia containing cubic crystal more than $30 \%$ by volume (group XT and P) showed significant decrease in flexural strength and fracture toughness. It is because the cubic zirconia structure is more stable phase and it reduces its potential for stress-induced transformation toughening. ${ }^{30}$ The average flexural strength and fracture toughness in cubic-containing group (cubic $>30 \%$ ) were lower than 500 $\mathrm{MPa}$ and $3.5 \mathrm{MPa} \mathrm{m}{ }^{1 / 2}$ respectively. Therefore it is recommended to used monolithic restoration for a three-unit fixed prosthesis not involving molar restoration, clinically. However, group ST containing cubic crystal less than $30 \%$ by volume presented higher amount of tetragonal structure for transformation toughening phenomenon. As a result, flexural strength for group ST was still greater than 500 MPa but not exceeding $800 \mathrm{MPa}$. Therefore, it can be recommended to fabricate prosthesis involving molar restoration with the span not more than four units. On the other hand, conventional zirconia in this present study exhibited the highest strength. Therefore, it is recommended for the fabrication of prostheses involving partially or fully covered substructure for four or more units. ${ }^{20}$

This study investigated in vitro accelerated hydrothermal aging characteristics of material using autoclave condition at $122^{\circ} \mathrm{C}$ under 2 bar pressure over a period of $8 \mathrm{~h}$. It is possible to assume that $1 \mathrm{~h}$ of autoclave aging in this condition has the same effect as 1 year in clinical services. ${ }^{31} \mathrm{X}$-ray diffraction analysis showed that there was no monoclinic phase presented after hydrothermal aging in group XT and P. The results indicated that high amount of cubic crystal caused a more stable condition of zirconia; therefore, $\mathrm{t} \rightarrow \mathrm{m}$ transformation did not occur. The present results correspond with a previous study evaluating the aging stability of $5 \mathrm{Y}-0.05 \mathrm{Al}$ after accelerated hydrothermal aging in steam at $134^{\circ} \mathrm{C}$ and $2 \mathrm{MPa}$ in water vapour. The authors reported that cubic zirconia did not show any transformation after $300 \mathrm{~h}$ of accelerated hydrothermal treatment. ${ }^{11}$ It can be assumed that a zirconia containing cubic crystal more than $30 \%$ by volume had a pronounced effect on retarding the hydrothermal degradation. On the contrary, zirconia containing less than 30\% by volume of cubic crystal exhibited the presence of monoclinic phase, which approximately $5.06 \%$ after hydrothermal aging for $8 \mathrm{~h}$. The negligible amount of monoclinic phase presented after aging in zirconia containing less than 30\% of cubic crystal was accepted in the engineering guidelines for use of zirconia-based materials. ${ }^{4}$ For conventional zirconia, the presence of monoclinic phase after autoclave aging was agreed in part with the finding of Kim et al., who evaluated the amount of monoclinic phase on IPS e.max ZirCAD (conventional zirconia) by XRD after $8 \mathrm{~h}$ of aging. Flinn $e t$ al. assessed the effect of aging on mechanical properties of zirconia. Based on their results, hydrothermal aging of conventional Y-TZP materials can cause a significant $\mathrm{t} \rightarrow \mathrm{m}$ phase transformation, which resulted in a statistically significant decrease in the mechanical properties of zirconia. ${ }^{8-10}$ Results of the above study corresponded to our present study, which reported that flexural strength and fracture toughness were reduced significantly after hydrothermal aging, especially in conventional group. On the other hand, some previous studies reported that dental zirconia had no significant difference in bulk properties such as flexural strength after aging. ${ }^{7}$ The present results showed that amount of cubic crystal more than $30 \%$ by volume could increase the hydrothermal aging resistance, even though the mechanical properties were significantly altered. More stable zirconia crystal results in decreased potential for $\mathrm{t} \rightarrow \mathrm{m}$ phase transformation after hydrothermal aging. ${ }^{11}$

Ramesh et al..$^{13}$ stated that a small grain size is beneficial in suppressing hydrothermal aging induced $\mathrm{t} \rightarrow \mathrm{m}$ phase transformation of Y-TZP. It was found that if grain sizes were below $0.5 \mu \mathrm{m}$, the $\mathrm{t} \rightarrow \mathrm{m}$ phase transformation was suppressed. The result of this study was not coinciding with result of previously mentioned study. It could be explained that the average grain size for group $P$ was $2.28 \mu \mathrm{m}$ and the $\mathrm{t} \rightarrow \mathrm{m}$ transformation did not occur after aging. However, the various processing condition to prepare the zirconia materials and the amount of yttria stabilizer added during powder 
preparation may affect the optimum grain size. ${ }^{13}$

Zirconia with no cubic content or high amount of tetragonal phase increases hydrothermal degradation and phase transformation, which could correspond to several mechanisms. ${ }^{32}$ Hydrothermal degradation is a process in which the transformation of tetragonal to monoclinic phase occurs because of humidity. Formation of the hydroxyl ions $\left(\mathrm{OH}^{-}\right)$in water molecules can diffuse into the zirconia lattice then water reacts with $\mathrm{ZrO}_{2}$ or $\mathrm{Y}_{2} \mathrm{O}_{3}$ bonds at crack tips. As a consequence, $\mathrm{Zr}-\mathrm{OH}$ or $\mathrm{Y}-\mathrm{OH}$ bonds are formed. The $\mathrm{Zr}-\mathrm{OH}$ or $\mathrm{Y}-\mathrm{OH}$ bond brings about the lattice strain on the surface. Strain accumulation creates nucleation sites for phase transformation on the surface; consequently, the metastable tetragonal transformation to stable monoclinic phase can occur. ${ }^{33-35}$ Therefore, when the amount of monoclinic was increased and continued from the external surface to the internal of material, the volume expansion by phase transformation and the degradation of the mechanical properties occurred. For this reason, the strengths of group $\mathrm{T}$ and ST were decreased. Further studies are required to investigate the other properties of the cubic-containing commercial translucent zirconia such as optical properties. Furthermore, researches are necessary to assess the longterm cyclic fatigue resistance of this type of zirconia. Lastly, the in vivo studies and wear characteristic of the cubic-containing commercial translucent zirconia should be evaluated.

\section{CONCLUSION}

Based on the limitations of this in vitro study, the mechanical properties evaluation showed that cubic-containing zirconia materials (group ST, XT, and P) exhibited lower flexural strength and fracture toughness than non-cubic 3Y-TZP zirconia (group T). However, hydrothermal aging in autoclave for $8 \mathrm{~h}$ caused a statistically significant decrease in the mechanical properties of non-cubic 3Y-TZP zirconia (group $\mathrm{T})$ and cubic-containing zirconia with the amount of cubic content less than $30 \%$ by volume (group ST), owing to the spontaneous $\mathrm{t} \rightarrow \mathrm{m}$ transformation. In addition, zirconia containing more than $30 \%$ by volume of cubic crystal (group XT and P) were assumed to have high resistance to low temperature degradation.

\section{ACKNOWLEDGEMENTS}

The authors gratefully thank Mrs. Chanya Chuena-rrom, Faculty of Dentistry, Prince of Songkla University for supporting in this work and we would like to thank all companies for access to the zirconia materials.

\section{ORCID}

Santiphab Kengtanyakich bttps://orcid.org/0000-0002-4797-6233 Chaimongkon Peampring https://orcid.org/0000-0003-2156-6022

\section{REFERENCES}

1. Gracis S, Thompson VP, Ferencz JL, Silva NR, Bonfante EA. A new classification system for all-ceramic and ceramic-like restorative materials. Int J Prosthodont 2015;28:227-35.

2. Denry I, Kelly JR. State of the art of zirconia for dental applications. Dent Mater 2008;24:299-307.

3. Kim JW, Covel NS, Guess PC, Rekow ED, Zhang Y. Concerns of hydrothermal degradation in CAD/CAM zirconia. J Dent Res 2010;89:91-5.

4. Lughi V, Sergo V. Low temperature degradation -aging- of zirconia: A critical review of the relevant aspects in dentistry. Dent Mater 2010;26:807-20.

5. Chevalier J. What future for zirconia as a biomaterial?. Biomaterials 2006;27:535-43.

6. Kim HT, Han JS, Yang JH, Lee JB, Kim SH. The effect of low temperature aging on the mechanical property \& phase stability of Y-TZP ceramics. J Adv Prosthodont 2009;1:113-7.

7. Alghazzawi TF, Lemons J, Liu PR, Essig ME, Bartolucci AA, Janowski GM. Influence of low-temperature environmental exposure on the mechanical properties and structural stability of dental zirconia. J Prosthodont 2012;21:363-9.

8. Flinn BD, deGroot DA, Mancl LA, Raigrodski AJ. Accelerated aging characteristics of three yttria-stabilized tetragonal zirconia polycrystalline dental materials. J Prosthet Dent 2012;108: 223-30.

9. Flinn BD, Raigrodski AJ, Singh A, Mancl LA. Effect of hydrothermal degradation on three types of zirconias for dental application. J Prosthet Dent 2014;112:1377-84.

10. Flinn BD, Raigrodski AJ, Mancl LA, Toivola R, Kuykendall T. Influence of aging on flexural strength of translucent zirconia for monolithic restorations. J Prosthet Dent 2017;117: 303-9.

11. Zhang F, Inokoshi M, Batuk M, Hadermann J, Naert I, Van Meerbeek B, Vleugels J. Strength, toughness and aging stability of highly-translucent Y-TZP ceramics for dental restorations. Dent Mater 2016;32:e327-37.

12. Baldissara P, Wandscher VF, Marchionatti AME, Parisi C, Monaco C, Ciocca L. Translucency of IPS e.max and cubic zirconia monolithic crowns. J Prosthet Dent 2018;120:269-75.

13. Ramesh S, Sara Lee KY, Tan CY. A review on the hydrothermal ageing behaviour of Y-TZP ceramics. Ceram Int 2018;44: 20620-34.

14. Kontonasaki E, Giasimakopoulos P, Rigos AE. Strength and aging resistance of monolithic zirconia: an update to current knowledge. Jpn Dent Sci Rev 2020;56:1-23.

15. Volpato CAM, Garbelotto LGA, Fredel MC, Bondioli F. Application of zirconia in dentistry: biological, mechanical and optical considerations. In: Sikalidis C, editor. Advances in ceramics? Electric and magnetic Ceramics, bioceramics, ceramics and environment. In Tech Open 2011. p. 397-420.

16. Carrabba M, Keeling AJ, Aziz A, Vichi A, Fonzar RF, Wood D, Ferrari M. Translucent zirconia in the ceramic scenario for monolithic restorations: A flexural strength and translucency comparison test. J Dent 2017;60:70-6.

17. Garvie RC, Nicholson PS. Phase analysis in zirconia systems. J Am Ceram Soc 1972;55:303-5. 
18. Toraya H, Yoshimura M, Somiya S. Calibration curve for quantitative analysis of the monoclinic-tetragonal $\mathrm{ZrO} 2$ system by X-ray diffraction. J Am Ceram Soc 1984;67:119-21.

19. Elsaka SE, Elnaghy AM. Mechanical properties of zirconia reinforced lithium silicate glass-ceramic. Dent Mater 2016;32: 908-14.

20. ISO 6872. Dentistry - Ceramic materials. International Standards Organization (ISO); Geneva; Switzerland, 2015. Available at: https://www.iso.org/obp/ui\#iso:std:iso:6872:ed4:v1:en

21. Anusavice KJ, Shen C, Rawls HR. Phillips' science of dental materials. 12th ed. St. Louis; Elsevier; 2013. p. 62, 454.

22. Wang H, Isgro G, Pallav P, Feilzer AJ. Influence of test methods on fracture toughness of a dental porcelain and a soda lime glass. J Am Ceram Soc 2005;88:2868-73.

23. Miyazaki T, Nakamura T, Matsumura H, Ban S, Kobayashi T. Current status of zirconia restoration. J Prosthodont Res 2013;57:236-61.

24. Church TD, Jessup JP, Guillory VL, Vandewalle KS. Translucency and strength of high-translucency monolithic zirconium oxide materials. Gen Dent 2017;65:48-52.

25. Zhang Y. Making yttria-stabilized tetragonal zirconia translucent. Dent Mater 2014;30:1195-203.

26. Sulaiman TA, Abdulmajeed AA, Donovan TE, Ritter AV, Vallittu PK, Narhi TO, Lassila LV. Optical properties and light irradiance of monolithic zirconia at variable thicknesses. Dent Mater 2015;31:1180-7.

27. Casolco SR, Xu J and Garay JE. Transparent/translucent polycrystalline nanostructured yttria stabilized zirconia with varying colors. Scr Mater 2008;58:516-9.

28. Abraham I, Gritzner G. Mechanical properties of doped cubic zirconia ceramics. J Mater Sci Lett 1993;12:995-7.

29. Garvie RC, Hannink RHJ, Pascoe RT. Ceramic steel?. Nature 1975;258:703-4.

30. Hannink RH, Kelly PM, Muddle BC. Transformation toughening in zirconia-containing ceramics. J Am Ceram Soc 2000; 83:461-87.

31. Chevalier J, Cales B, Drouin JM. Low-temperature aging of Y-TZP ceramics. J Am Ceram Soc 1999;82:2150-4.

32. Guo X. Property degradation of tetragonal zirconia induced by low-temperature defect reaction with water molecules. Chem Mater 2004;16:3988-3994.

33. Sato T, Shimada M. Transformation of yttria-doped tetragonal $\mathrm{ZrO} 2$ polycrystals by annealing in water. J Am Ceram Soc 1985;68:356-9.

34. Lange FF, Dunlop GL, Davis BI. Degradation during aging of transformation-toughened $\mathrm{ZrO} 2-\mathrm{Y} 2 \mathrm{O} 3$ materials at 250 C. J Am Ceram Soc 1986;69:237-40.

35. Yoshimura M, Noma T, Kawabata K, Somiya C. Role of $\mathrm{H} 2 \mathrm{O}$ on the degradation process of Y-TZP. J Mater Sci Lett 1987;6:465-7. 